\title{
Receptum arbitrii
}

CÁNDIDA GutiérRez

En el estudio del Receptum arbitrii, instituto romano cuya finalidad consistía en hacer posible la solución de desavenencias o litigios existentes entre dos o más personas mediante el recurso a un arbiter, esto es, sin tener que someterse a las exigencias que imponía la vía judicial, se ha pretendido poner de manifiesto, en principio, el significado y alcance que tuvieron determinados factores extrajurídicos.

Por ello el método interdisciplinar constituía una exigencia que venía impuesta por la lógica interna misma de la institución, como forma concreta adecuada para ampliar y profundizar las líneas esenciales de la investigación. Evidentemente, y supuesta la naturaleza misma de este trabajo de investigación, exige el mantenerse siempre fiel a los criterios básicos en que se inspira el método histórico-crítico, tanto para comprender la evolución de este instituto como para valorar y resaltar el alcance real que tuvieron las alteraciones que presentan los textos en las fuentes.

En primer lugar se analizan las diferentes acepciones que el término recipere tiene en las fuentes literarias y jurídicas, con el fin de entender más profundamente el sentido que adquirió posteriormente este término al ser asumido por el Pretor en su Edicto, sancionando jurídicamente la aceptación explícita de responsabilidad por parte de determinados profesionales, como eran el nauta, caupo, stabularius, y argentarius, $\mathrm{y}$ en especial por lo que se refiere al instituto que aquí se trata, la responsabilidad aceptada voluntariamente por el arbiter ex compromisso.

Después de comprobar que eran muchos los significados de receptum y de recipere en la literatura latina y que van desde una dimensión 
puramente material, como sería la adquisición de la posesión de una cosa o la recuperación de algo, hasta otros de contenido abstracto en los que adquiere el sentido de «aceptación estricta de una obligación». Esta última es precisamente la que se desprende del Edicto del Pretor, cuando alude a la responsabilidad asumida de forma explícita por quienes así lo han querido. De forma particular hemos subrayado en el estudio el hecho de que la palabra recipere fue utilizada por los juristas en numerosos textos con el sentido de «exigencia de responsabilidad». En otras palabras, en Roma, quienes venían dispuesto a asumir voluntariamente una responsabilidad, lo manifiestan utilizando el verbo recipere.

A continuación, y centrándonos en el estudio de los Recepta en el Edicto del Pretor se pone de manifiesto ante todo por qué se justifica el estudio conjunto de estos institutos. No hemos tenido sólo presente el fundamento jurídico edictal común, sino que prestamos atención también a razones históricas.

Procedemos a exponer las razones de Lenel a negar la existencia de una conexión interna entre los recepta, en cuanto que, según él, los dos últimos sólo aparecían junto al primero por el hecho de que también en ellos la aceptación de la obligación se designa con la palabra recipere. Sin embargo, no parece convincente la tesis que ve sólo una conexión verbal entre los dos recepta. La semejanza de nombre sin ningún otro punto de contacto no es motivo suficiente para llevar al Pretor a reunir estos negocios jurídicos bajo un mismo título en el Edicto. Es muy posible que exista semejanza en cuanto a la naturaleza jurídica a la que obedecen, esto es, que todos ellos participan de un fundamento jurídico común.

Abordamos también el estudio de la naturaleza jurídica de los recepta exponiendo las razones por las que pueden ser considerados como nudos pactos ni contratos consensuales. Pudiendo concluir que estos recepta constituirían cláusulas de aceptación de una responsabilidad estricta añadida a un negocio jurídico básico.

Posteriormente analizamos sucesivamente la estructura y contenido compromissum como requisito previo para someterse a continuación 
a la decisión de un árbitro las partes que pretenden solucionar a la decisión de un árbitro las partes que pretenden solucionar sus controversias por este medio. Exponemos las obligaciones de las partes antes y después de la sentencia arbitral, para estudiar inmediatamente, los efectos del compromissum y los supuestos de su extinción. Por último hacemos un estudio detallado de la función del arbitraje privado y su semejanza con el arbitraje público - los elementos comunes que presentan ambos. Destacamos que sea cual sea la dificultad existente para determinar el perfil exacto del arbiter y del iudex en la época más antigua, en el caso del arbiter ex compromisso, es posible conocer sus características y las causas que le incapacitan para ejercer como tal, teniendo en cuenta la doctrina en el D,4,8.

En particular se explica en qué sentido el arbiter debía actuar de acuerdo con el derecho objetivo y las normas en que éste se expresa y cómo la eventual no sugeción del árbitro a esas normas podía encontrar su sanción.

En cuanto a los poderes del árbitro subrayamos como son prácticamente los mismos del juez y, teniendo un mismo fin el árbitro disponía de los mismos medios para alcanzarlo.

Después de hacer una breve referencia a la distinción arbiter-sequester y arbiter-iudex analizamos por último el receptum arbitrii refiriéndonos en primer lugar a la aceptación del árbitro y a la forma en que debía llevarse a efecto el pacto de receptum arbitrii.

La exposición concluye con el estudio de la responsabilidad del árbitro y las dificultades que ha planteado en la doctrina la sanción del mismo por el incumplimiento del receptum pues limitándose el Pretor a expresar un genérico cógere no podemos extraer una conclusión precisa, en cuanto que puede hacer referencia a cualquier tipo de coercitio de las que dispone el magistrado. Llegamos a la conclusión de que no existen datos en las fuentes que permitan afirmar de forma categórica la existencia de acción alguna contra el árbitro incumplidor.

Para completar la exposición hacemos referencia también a las reformas introducidas por Justiniano en relación con la institución del 
tribunal arbitral y, en particular, subrayamos la introducción de una verdadera actio in factum para exigir la sentencia de los árbitros cuando las partes así lo hubieran expresamente acordado. 